\title{
Designing an algorithm for the use of Suprathel@ following enzymatic debridement with Nexobrid® in burn injuries in hands
}

Autors: dos Santos BP, Serracanta J, Aguilera-Sáez J, Verdaguer E, Barret JP

\section{Objectives}

Describe our experience using Suprathel ${ }^{\circledR}$ after enzymatic debridement of burn injuries located in hands

\section{Methods}

Patients presenting with second degree intermediate burns located in their hands whether inpatient or outpatient were treated with enzymatic debridement with Nexobrid ${ }^{\circledR}$

Next day assessment of the wound bed resulted in some patients moving from intermediate to predominantly deep or superficial second degree.

Patients with predominantly superficial or intermediate wound beds after debridement were treated with Suprathel@ covered with a sheet of Urgotul® and a dry sterile gauze the latter were removed every 5 days so as to trim Suprathel® and Urgotul@ covering epithelized wound bed

\section{Results}

Patients treated sequentially with Nexobrid® ${ }^{\circledR}$ and then Suprathel ${ }^{\circledR}$ showed as per the literature and our experience a similar delayed healing time as is expected with Nexobrid® alone. Nonetheless patients who underwent adjunctive treatment with Suprathel® required less surgical debridement and grafting

NXB

\section{Wound bed classification}

\section{Secondary} treatment

\section{Outcome}

\begin{tabular}{|c|c|}
\hline Wound bed appearance & Depression \\
\hline $\begin{array}{l}\text { Abundance of small diameter pin- } \\
\text { point bleeders (uniform shades of } \\
\text { red to pink) }\end{array}$ & No \\
\hline $\begin{array}{l}\text { Sparse pattern of larger diameter } \\
\text { bleeders (irregular shades of pink } \\
\text { to white) }\end{array}$ & No \\
\hline $\begin{array}{l}\text { Sparse pattern of larger diameter } \\
\text { bleeders (no shades of white } \\
\text { color) }\end{array}$ & Yes \\
\hline Fatty & Yes \\
\hline
\end{tabular}

\begin{tabular}{l} 
Wound bed classification afiter do \\
\hline Type I \\
\hline Type lla \\
\hline Type Illo \\
Type III
\end{tabular}

PT: Partial thickness, FT: Full thickness

Source:

Ricard P, Aguilera-Sáez J, Serracanta J, Delfa JM, dos Santos BP, Barret JP. Use of a selective enzymatic debridement

agent (Nexobrid ${ }^{\circledast}$ ) for wound management: Learning curve. World Journal of Dermatology (2017) 6. 32-41. 10.5314/wjd.v6.i2.32.

\section{Type of burn Superficial PT \\ Mid/deep PT \\ Deep PT \\ FT}

scan and enzymatic debridement, the latter has somewhat lifted the veil from the preconceived pattern experience has taught us to recognize and assess an "uncontaminated" wound bed were the depth of dermal involvement is more readily apparent.

-This process of selective debridement that allows for a reconsideration of our diagnostic acumen also leaves the wound bed more vulnerable to desiccation and might even remove some of the extracellular cues that trigger proper wound healing, and it is for this reason that Suprathel ${ }^{\circledR}$ complements the process of enzymatic debridement by providing a flexible porous membrane that mimics the protective properties of healthy epithelium with a high capacity for water absorption creating an ideal environment for wound healing 